Session 3157

\title{
Using a Communication Lab to Integrate Workplace Communication into Senior Design"
}

\author{
Judith Shaul Norback, Joel S. Sokol, \\ Garlie A. Forehand, Beverly Sutley-Fish \\ School of Industrial and Systems Engineering \\ Georgia Institute of Technology
}

\begin{abstract}
Recently engineering students whose training has traditionally focused on preparing them for the technical aspect of the workplace are receiving more instruction in communication. Senior Design courses offer an excellent opportunity for enhancing students' writing and presenting skills because of the communication required between student teams, their clients, and their professors. At the School of Industrial and Systems Engineering (ISyE) at Georgia Tech, job communicative analysis, a systematic approach to identifying the writing and presenting demands of jobs, has been used to provide the basis for workplace communication instruction. During workplace interviews with practicing industrial engineers, supervisors, and CEOs, information and workplace examples have been collected. The information has been used to develop a list of criteria for communication excellence: the basis for developing workplace communication instruction to integrate with Senior Design. This article describes the use of the ISyE Communication Lab to implement and support the instruction. Lab activities and instructional tools will be covered as well as faculty and student feedback. The instructional tools will be made available to other institutions for use in their undergraduate engineering courses.
\end{abstract}

\section{Introduction}

In recent years, emphasis has increased on preparing engineering students for the communication needs of the workplace. In 2000, the Accreditation Board for Engineering and Technology (ABET) included oral and written communication in its accreditation criteria. ${ }^{1}$ In 1999, the Society of Manufacturing Engineers conducted a survey of manufacturing engineers, managers, and training directors. Two of the conclusions were 1) the oral and written skills of engineering

\footnotetext{
* This work was supported in part by the National Science Foundation under Grant DUE-0231305.
}

Proceedings of the 2004 American Society for Engineering Education Annual Conference \& Exposition Copyright $(\mathbb{C}$ 2004, American Society for Engineering Education 
graduates are not high enough to meet job demands, and 2) this discrepancy in oral and written skills is one of the 10 most critical gaps. ${ }^{2}$

The School of Industrial and Systems Engineering at Georgia Tech has integrated workplace communication instruction into its Senior Design courses for the past three years. The instruction is based upon the use of job communicative analysis, a systematic process designed to identify the writing and presenting skills required in the workplace. The process involves interviews with industrial engineers, supervisors, and senior executives. The instructional materials and techniques built from the workplace research have been integrated into Senior Design through the use of a Communication Lab. The activities and instructional tools implemented in class and in the Lab will be described in this paper.

\section{Background}

Many studies have shown that engineers need good communication skills and have suggested a variety of educational emphases. ${ }^{3456}$ Much of the engineer's time on the job is spent communicating. Two studies from $1996^{7}$ and $2001{ }^{6}$ found that engineers spend more than half of their time communicating with others in writing and through oral discussions and presentations.

The information used to teach effective communication needs to come directly from the workplace. Linguistic research describes the different discourse communities of academia and the workplace. ${ }^{8}$ Expectations and shared knowledge are very different in the two settings. In order for communication instruction to be effective, it must conform to the needs and expectations of the workplace rather than academia.

Other research emphasizes the need for instruction with "high functional context". 9 If information and materials from the workplace, or the context in which the student will need to function well, are brought into the instructional setting, students are much more likely to apply what they learn in their courses to their work on the job.

One 2003 study described a variety of approaches used by institutions to enhance their engineering students' communication skills. ${ }^{10}$ The four approaches were 1) writing across the engineering curriculum, 2) interdisciplinary courses, 3) integrated communication and engineering programs, and 4) support systems such as communication labs and writing centers. A number of institutions are beginning to use communication labs to support oral, or both oral and written, instruction for engineering undergraduates. ${ }^{11}$ The National Communication Association 2001 conference highlighted the experiences of schools including Virginia Tech, the University of Richmond, Mount Holyoke College, the College of San Mateo, Ithaca College, the University of Colorado at Colorado Springs, and Southwest Texas State. ${ }^{12}$

The ISyE Communication Lab at Georgia Tech has built upon what has been done previously at other institutions. In addition, it has emphasized educational application of detailed instances collected from practicing engineers, supervisors and Chief Executive Officers (CEOs). The Job 
Communicative Analysis process used will be described, and then the Lab activities will be covered along with the instructional tools.

\section{Job Communicative Analysis}

In Job Communicative Analysis, practicing engineers and supervisors are interviewed in person. They are asked to set aside the most important materials they write and create to use in presentations. For each material-whether it is an email, status or technical report, technical specifications, white paper, meeting minutes, or slides — the professionals are asked the following:

1) Who is the audience for the material? Is the audience technical or non-technical?

2) What is the purpose of the material?

3) How important is the material to getting your job done?

4) What steps are used to create it?

5) How do you determine when the material is well done?

6) Do new hires create similar material? If so, how important is it to performing their job?

The personal interviews result in the collection of a range of workplace materials along with information about each one. In addition to the personal interviews, telephone interviews are conducted with CEOs. They are asked to identify the two or three most important communication skills needed by engineers who work for their company. The results of all the interviews are used to identify communication skills needed by graduating engineering students. ${ }^{13141516}$ These skills form the basis for the activities and instructional tools used in the Communication Lab.

\section{Communication Lab Activities}

The Communication Lab provides instruction and practice focused on effective communication as an integral part of engineering design work. Some lab activities take place in class in coordination with design projects. Other activities take place in the Lab where the focus is on service to individual students and teams. The activities include:

1) interactive discussions about audience analysis, presentation, and writing skills

2) panel discussions about workplace communication skills by recent graduates and senior executives

3) videotaping of in-class presentations with follow-up review and practice in the Lab

4) writing instruction and review in the Lab.

These activities and the instructional tools will be described briefly below. The instructional tools will be included in the conference presentation. 
In-Class overviews of communication skills. The first type of activities is in-class overviews of audience analysis skills, presentation, and writing skills. In one overview, students fill out the audience analysis tools for their particular client. Topics covered in the tool are:

1) What role does each of your client contacts play?

2) What is their level of authority?

3) What do they expect the project outcome to be?

4) What do they value the most?

The students are asked to fill out the tools individually and then discuss their analysis with their team members. Interactive discussion in the beginning of Senior Design often reveals that individual analyses are different. Students fill out the audience analysis tools as a team several times over the course as they gain more understanding of and information about their client.

In the same overview, presentation pointers are described. This instructional tool includes a subset of the skills from the Norback Criteria for Communication Excellence chosen by the faculty teaching the course. The types of skills covered, along with examples, are:

1) conveys ideas and results (for example, including only relevant content in the presentation, emphasizing important information on the slides through the use of color or font, and including graphs and charts that are easy to understand)

2) stays professional (for instance, avoiding distracting gestures, transitioning smoothly to the next speaker, and using appropriate language)

3) keeps the audience's attention (for example, maintaining good eye contact, responding appropriately to audience requests for clarification, and using inflection and voice modulation effectively)

The skills are demonstrated in the overview and illustrative examples from the workplace interviews are described. The discussion is interactive, with students providing examples of their own from the client projects.

A similar overview is given for workplace writing skills. Again, the skills are chosen by the Senior Design faculty from the same Criteria, and include the following:

1) conveying ideas and/or results (for instance, providing adequate support for conclusions)

2) structure and organization (for example, logical flow)

3) writing style (for instance, editing input from multiple authors so the text reads as if it had a single author).

In the overview, specific workplace examples are used to illustrate the skills.

Panels of workplace professionals. A second type of activity involves two kinds of panels of workplace professionals. The purpose of the panels is to increase student awareness 1)of the

Proceedings of the 2004 American Society for Engineering Education Annual Conference \& Exposition Copyright (C) 2004, American Society for Engineering Education 
importance of effective communication on the job, and 2) of the skills they can enhance during the Senior Design experience. A panel of recent graduates and a panel of senior executives visit class for an interchange with students on the communication skills needed in the workplace, based on their experience. The panelists point out the skills on the criteria of communication excellence that are most important in their jobs. Recent graduates often describe their first day on the job and communication skills they have had to learn along the way. For instance, one recent graduate had to give a presentation during his first day on the job, based on information he had received earlier that same day. Another recent graduate described learning to be concise by receiving repeated instructions from his boss to fix the multiple drafts of a report he turned in. The boss only stopped returning the draft to the engineer when the report was finally sufficiently concise.

The senior executives focus on communication skills needed by engineers in their companies and specifically by engineers interacting with them. For example, one CEO mentioned that he needed to know right away what kind of decision was needed based on the communication, and how the decision would affect the bottom line. Another CEO related an incident where he told an engineer he had only five minutes to give a presentation that was prepared with the expectation of a 15-minute time slot. When the engineer started to give the prepared talk with no modifications, the CEO sent him away and asked him to return with a briefer talk.

Other topics for both the recent graduate panels and the senior executive panels have ranged from email to handling meetings to changing jobs to building trust through accurate communication.

Videotaping class presentations. The third type of activity supported by the Communication Lab is the videotaping of all class presentations. The presentations are preparation for client presentations, so feedback is provided to students in the Lab before they present to their clients. During classroom presentations, students are asked to interrupt the presenters with questions so the presenters are more prepared to deal with client questions. Different student teams role-play engineers in the client audience and managers in the client audience, to give presenters experience answering both technical questions and higher-level concerns. While presentations and questioning are going on, other teams use the Presentation Pointers tool to provide feedback to their peers. These forms are also filled out by the supervising faculty and communication expert.

When the videotape is reviewed in the Lab, the comments by the faculty, the communication expert, and the students are reviewed. The students who presented play an active role in critiquing themselves and each other. Focus is placed on areas that are done well along with those needing improvement. As part of the review in the Lab, students practice improving their skills by, for instance, editing their slides on the spot to be more concise or to have a better logical flow, and by presenting part of their talk again taking into account the feedback they just received. 
Writing instruction. Individual and group writing instruction is the fourth type of activity supported by the Communication Lab. Lab staff provide in-person consultation based on the Writing Pointers tool and basic grammar, spelling, and structural issues. Lab staff use examples from the students' draft materials to illustrate general points and then ask the students to practice applying the principles under the staff's guidance.

\section{Continuous faculty and student input}

As described above, Senior Design faculty play an active role in designing the instructional tools by selecting the workplace skills they think their students are most in need of learning. They have also suggested several skills that have come up based on student performance in class. For example, "giving an informative presentation" and "using a logical flow" were added because of faculty input. In addition, some workplace skills have been dropped from the tools (although they remain in the Criteria for Communication Excellence) because they seemed by faculty to be higher-level communication skills. One example is the skill of assessing the audience for evidence of disagreement and responding appropriately. These skills may be included in future Senior Design courses. Faculty have also recommended future activities such as the culmination of the Senior Design courses with a competition for the best presentation. The judges would include senior executives as well as faculty.

Student feedback was gathered during the first three semesters of workplace communication instruction and has been reported separately (IEE article). During the past two semesters the Communication Lab has supported all of the instructional activities described above. Input from students regarding the Lab activities is now being collected and will be included in the conference presentation.

\section{Future work}

In the future the activities of the Communication Lab will continue to be modified based on faculty and student assessment. Lab activities will expand to support other courses. For example, currently a project funded by the National Science Foundation is underway to integrate workplace communication instruction into the Technical Communication course.

\section{Bibliography}

\footnotetext{
1 "2000-2001 Criteria for Accrediting Engineering Programs," Accreditation Board of Engineering and Technology, Baltimore, 2000.

${ }^{2}$ Rogers, Dick, Jr.; M.J. Stratton; and R.E. King. "Manufacturing Education Plan: 1999 Critical Competency Gaps - Industry Updates Competency Gaps Among Newly Hired Engineering Graduates," Society of Manufacturing Engineers, 1999

${ }^{3}$ Pinelli, T.E.; R.O. Barclay; and J. M. Kennedy. "Workplace Communication Skills and Value of Communications and Information UseSkills Instruction-Engineering Students' Perspectives.” Proceedings of the IEEE Int'l Communication Conference, 1995: 161-165.
} 


\footnotetext{
${ }^{4}$ Schillaci, William C. "Training Engineers to Write: Old Assumptions and New Directions," Journal of Technical Writing and Communication, v26 n3 (1996): 325-333.

${ }^{5}$ Rogers, Dick, Jr.; M.J. Stratton; and R.E. King. "Manufacturing Education Plan: 1999 Critical Competency Gaps-Industry Updates Competency Gaps Among Newly Hired Engineering Graduates.” Technical Report for the Society of Manufacturing Engineers, 1999.

${ }^{6}$ Sageev, Pneena and Carol J. Romanowski. "A Message from Recent Engineering Graduates $n$ the Workplace: Results of a Survey on Technical Communication Skills.” Journal of Engineering Education, v90 n4 (October 2001): 685-693.

${ }^{7}$ Vest, David; Marilee Long; and Thad Anderson. "Electrical Engineers' Perceptions of Communication Training and Their Recommendations for Curricular Change: Results of a National Survey." IEEE Transactions on Professional Communication, v39 n1 (March 1996): 38-42.

${ }^{8}$ Booth, Wayne C.; Gregory G. Colomb; and Joseph M. Williams. The Craft of Research, University of Chicago Press, Chicago, 1995.

Kryder, LeeAnne G. "Mentors, models and clients: using the professional engineering community to identify and teach engineering genres." IEEE Transactions on Professional Communication, v42 n1 (March 1999): 3-11.

${ }^{9}$ Norback, Judith Shaul. "Literary Skills Analysis for Job Training." NCAL Technical Report TR98-07, National Center on Adult Literacy, University of Pennsylvania, Philadelphia, 1998.

Norback, Judith Shaul and Garlie A. Forehand. "Print Use Profiles." Occupations and the Printed Word, ed. P. Barton, ETS Policy Information Center, 1997.

Norback, Judith Shaul. "Skill Levels and Equivalencies: Related Projects and Issues." Strategy Paper for the National Skill Standards Board, Institute for Educational Leadership, Inc., Washington, D.C., 1996.

Norback, Judith Shaul and Garlie A. Forehand. "Job Literacy: A Framework for Categorizing Skills and Assessing Complexity." Technical Paper for the Center for Skills Enhancement, Inc., Princeton, NJ, 1995.

Norback, Judith Shaul. "The Norback Job Literacy Structure." Technical Paper for the Center for Skills Enhancement, Inc., Princeton, NJ, 1995.

Mikulecky, L. and P. Lloyd. "The Impact of Workplace Literacy Programs: A New Model for Evaluating the Impact of Workplace Literacy Programs.” NCAL Technical Report TR93-2, National Center on Adult Literacy, University of Pennsylvania, Philadelphia, 1993.

${ }^{10}$ Ford, Julie Dyke and Linda Ann Riley, "Integrating Communication and Engineering Education: A Look at Curricula, Courses, and Support Systems," Journal of Engineering Education October 2003: 325-328.

${ }^{11}$ Morreale, Sherwyn P., "Communication labs enhance student learning and promote awareness of the discipline," website of National Communication Association, http://www.natcom.org/Instruction/Resources/commlabs1098.htm

12 Proceedings from the Communications Lab Strand at the NCA 2001 Summer Conference, website of National Communication Association, http://www.natcom.org/Instruction/summerconf/commlabs.htm.

${ }^{13}$ Norback, Judith Shaul, Joel S. Sokol, Peter J. McGuire, Garlie A. Forehand. "Engineering Workplace Communication: Presenting and Writing." In Introduction to Engineering through Case Studies, editors Chetan Sankar and P.K. Raju. Taveneer Publishing Company, Anderson, SC, 2004.

${ }^{14}$ Norback, Judith Shaul, Jill R. Hardin, Beverly Sutley-Fish, and Stephanie A. Jernigan. "Integrating Workplace Communication into Senior Design." IEEE Transactions on Professional Communication, submitted for publication, 2004.

${ }^{15}$ Norback, Judith Shaul; G.A. Forehand; Stephanie A. Jernigan; Alexander B. Quinn. "Teaching Workplace Communication in Senior Design." Proceedings of the 2002 American Society for Engineering Education Conference, June 2002.

${ }^{16}$ Norback, Judith Shaul; Donna C. Llewellyn; Jill R. Hardin. "Integrating Workplace Communication into Undergraduate Engineering Curricula." OR/MS Today, v28 n4 (August 2001): 33-35.
} 


\title{
Biographical Information
}

\author{
JUDITH NORBACK \\ Dr. Judith Shaul Norback is the Director of Workplace and Academic Communication in Industrial and Systems \\ Engineering and a faculty member at Georgia Tech. Her research focuses on workplace communication skills \\ needed by practicing engineers. She has led the workplace communication research, coordinated the activities in the \\ lab, and co-authored the communication instruction for undergraduate engineers.
}

\section{JOEL S. SOKOL}

Dr. Joel S. Sokol is an Assistant Professor in the School of Industrial and Systems Engineering at Georgia Tech. His educational research interests include communication and the teaching of modeling. His technical work is in linear programming, inverse optimization, and combinatorial optimization, as well as the application of operations research techniques to logistics, biology, and network design problems.

\section{GARLIE A. FOREHAND}

Dr. Garlie A. Forehand was Director of Research Program Planning and Development at Education Testing Service until February 2000. Garlie teaches and consults in the areas of research design and workplace communication. His research emphasizes curriculum innovation and evaluation. As a consultant to Georgia Tech, Garlie has assisted in the workplace communication research and the communication instruction for engineering undergraduates.

\section{BEVERLY SUTLEY-FISH}

Dr. Beverly Sutley-Fish has experience in curriculum development and training in both academic and workplace settings. Beverly teaches and consults in the areas of organizational behavior, qualitative research and interpersonal communication. As a consultant to Georgia Tech, Beverly has assisted in the workplace communication research. 